\title{
Identification and characterization of low density polyethylene- degrading bacteria isolated from soils of waste disposal sites
}

\author{
Lalina Maroof ${ }^{\dagger}$, Ibrar Khan ${ }^{1}$, Han Sang Yoo $^{2}$, Suji Kim², Hong-Tae Park ${ }^{2}$, Bashir Ahmad ${ }^{1}$, \\ Sadiq Azam ${ }^{1}$ \\ ${ }^{1}$ Centre of Biotechnology and Microbiology, University of Peshawar, Pakistan \\ ${ }^{2}$ Department of Infectious Diseases, College of Veterinary Medicine, Seoul National University, South Korea
}

\begin{abstract}
The current study focused on an environment friendly method for degradation of Low Density Polyethylene (LDPE) using bacteria. A total of 36 bacterial strains were isolated from waste disposal sites in which six strains showed potential biodegradation activities. In this study, we reported 2 new strains i.e. Bacillus siamensis and Bacillus wiedmannii for LDPE degradation. The percent weight loss of LDPE films for isolates was; B. siamensis $(8.46 \pm 0.3 \%)$, B. cereus $(6.33 \pm 0.2 \%)$, B. wiedmannii $(5.39 \pm 0.3 \%)$, B. subtilis $(3.75 \pm 0.1 \%), P$. aeruginosa $(1.15 \pm 0.1 \%)$ and A. iwoffii $(0.76 \pm 0.1 \%)$ after $90 \mathrm{~d}$ of incubation. The LDPE films showed slight surface disruption as observed in Field Emission Scanning Electron Microscopy (FE-SEM) and Fourier Transform Infrared Spectroscopy (FTIR) showed formation of typical carbonyl peaks which were markedly reduced after incubation as measured by carbonyl index. The X-Ray Diffraction (XRD) analysis presented an increase in percent crystallinity and there was no apparent change in total carbon percentage. Different genes responsible for degradation of LDPE like Laccase (167 bp), Alk1 $(330 \mathrm{bp})$ and Alk2 (185 bp) were identified in bacterial isolates and further sequenced. The low degradation values in this study indicate that LDPE degradation is a slow, continuous and time dependent process.
\end{abstract}

Keywords: Bacillus siamensis, Bacillus wiedmannii, Biodegradation, Low Density Polyethylene

\section{Introduction}

Polyethylene (PE) is man-made polymers used in many aspects of human life. It is widely used due to its light weight, inexpensive, strong and durable nature. The worldwide production rate of synthetic polymers is about 140 million tons and its utility is increasing at the rate of $12 \%$ per annum [1]. Approximately 500 billion to 1 trillion Low Density Polyethylene (LDPE) bags are consumed annually around the globe, this enormous production and utilization of LDPE leads to their accumulation in the environment. Since $\mathrm{PE}$ is characteristically resistant to natural degradation, due their strong $\mathrm{C}-\mathrm{H}$ and $\mathrm{C}-\mathrm{C}$ bond, their disposal evokes a big ecological issue and is one of the leading sources of pollution [2]. Thus the rapid biodegradation of plastics has been a subject of interest as the disposal strategies are critical and need attention as it makes up to $40 \%$ of total municipal waste [3]. Moreover, oceans are getting contaminated with plastic wastes and marine animals by chance, ingest the plastics leading to their death [4].

Different methods are used for the degradation of LDPE including physical, chemical and biological methods. The physical and chemical methods are expensive, producing toxic wastes which in turn pollute the environment. On the other hand, biodegradation by microorganisms have become the focus of interest for eco-friendly disposal of plastics. Biodegradation is the result of utilization of a polymer as a carbon source by the microorganisms. These microorganisms produce extracellular enzymes which lead to chain cleavage of polymer into small monomers and oligomers. These are taken up by microbial cells and are metabolized into water and carbon dioxide $[5,6]$.

Several microorganisms have been reported to degrade LDPE, however, its high molecular weight, hydrophobic nature and lack of functional groups, recognized by microbial enzymes makes it adverse towards degradation [7]. Different treatments like Ultra Violet (UV), thermal and chemical, leads to the oxidation of the
This is an Open Access article distributed under the terms of the Creative Commons Attribution Non-Commercial License (http://creativecommons.org/licenses/by-nc/3.0/) which permits unrestricted non-commercial use, distribution, and reproduction in any medium, provided the original work is properly cited.

Copyright (C) 2021 Korean Society of Environmental Engineers
Received March 31, 2020 Accepted June 24, 2020

${ }^{\dagger}$ Corresponding author

Email: mlaleena@ymail.com

Tel: +92-336-9212496

ORCID: 0000-0002-2996-7931 
polymer surface and decreases the hydrophobicity of the surface favoring the microbial degradation [8]. The biodegradation assay was performed with variable range of cultural conditions. Different studies reported an in-vitro biodegradation of LDPE films in liquid culture system for $40-120 \mathrm{~d}$ of incubation at $30-37^{\circ} \mathrm{C}$ and $120-180$ rpm [2, 8-12].

Microorganisms such as Brevibacillus spp, Aneurinibacillus spp [13], Bacillus cereus, Brevibacillus borstelensis [14], Pseudomonas aeruginosa [15] and Enterobacter spp [16] have been reported in recent studies to degrade LDPE. Other studies showed Acinetobacter baumannii, Micrococcus luteus, Bacillus spp and Staphylococcus spp [17], Bacillus vallismortis, Pseudomonas protegens, Stenotrophomonas spp and Paenibacillus spp [18] to be involved in biodegradation. Various studies have been done to investigate the efficacy of genus Bacillus and are most frequently identified among LDPE biodegrading genera. Which includes $B$. cereus, $B$. thuringiensis, B. subtilis, B. pseudomycoides, B. mycoides, B. toyonesis, B. sphericus and $B$. amyloliquefaciens [7, 9, 10, 14, 19-21].

Different group of enzymes have been reported to degrade LDPE including laccase from Rhodococcus ruber. As a result of polymer chain scission and oxidations, a reduction in the molecular weight and increase in the carbonyl groups were observed after two weeks of incubation [22]. Laccase, reported from Trametes vasicolor and $B$. cereus has been reported to reduce the molecular weight of LDPE [23, 24]. Another important enzyme, alkane hydroxylase from ALK-B family, has also been reported for degradation of LDPE $[25,26]$. Alkane hydroxylase system from $P$. aeruginosa E7 showed $30 \%$ of degradation, a good indication of using them for biodegradation [15].

Landfills are the oldest and most common method of plastic waste disposal. Several studies has reported the PE degrading microorganisms from these waste disposal sites [14, 27]. This is the first study on isolation of local bacteria from waste disposal sites in Peshawar, Khyber Pakhtunkhwa (KP), Pakistan for LDPE degradation and we found two newly reported Bacillus strains, which can degrade LDPE efficiently. Moreover, we also confirmed that these isolates possess a Laccase and Alkane hydroxyase- producing gene which is the molecular explanation for the degradation of LDPE.

\section{Material and Methods}

\subsection{Chemicals and Polyethylene Films}

Additive free LDPE films of 230 micron thickness (ET311351/2, Goodfellow Cambridge Limited Huntingdon, England) were used in this study. Each film was cut into $2 \mathrm{~cm} \times 2 \mathrm{~cm}$ pieces and was subjected to heat at $70^{\circ} \mathrm{C}$ for $10 \mathrm{~d}$ followed by irradiation for $20 \mathrm{~d}$ with equal exposure on either side under UV $365 \mathrm{~nm}$ lamp (SANKYO DENKI, $8 \mathrm{~W}$ Japan). After pretreatments, LDPE films were disinfected with universal disinfectant $(10 \mathrm{~mL}$ bleach and $7 \mathrm{~mL}$ Tween 80 in $983 \mathrm{~mL} \mathrm{~d} \mathrm{H}_{2} \mathrm{O}$ ) for 30-60 min. The films were transferred into sterile distilled water and stirred for $30 \mathrm{~min}$ followed by placing in $70 \%$ ethanol for $30 \mathrm{~min}$. All the films were allowed to dry overnight at $60^{\circ} \mathrm{C}$, prior to subjected in further experimental work $[21,28]$. Mineral Salt Media (MSM) was prepared by using $0.5 \mathrm{~K}_{2} \mathrm{HPO}_{4}, 0.04 \mathrm{KH}_{2} \mathrm{PO}_{4}, 0.1 \mathrm{NaCl}, 0.002 \mathrm{CaCl}_{2} .2 \mathrm{H}_{2} \mathrm{O}$, $0.2\left(\mathrm{NH}_{4}\right)_{2} \mathrm{SO}_{4}, 0.02 \mathrm{MgSO}_{4} .7 \mathrm{H}_{2} \mathrm{O}, 0.001 \mathrm{FeSO}_{4}$ and $0.01 \mathrm{MnSO}_{4}$ in $\mathrm{g} / \mathrm{L}$ of sterile double deionized distilled water followed by adding $0.1 \%$ Tween 80 and stirred well for $1 \mathrm{~h}$ [8]. All reagents used in this study were of analytical grade.

\subsection{Sample Collection and Isolation of Low Density Polyethylene Degrading Bacteria}

Soil samples were collected from waste disposal sites in Peshawar, KP, Pakistan. Since these sites have been used to dump plastic bags for a very long time (10-20 years) and hence have increased probability of potent LDPE degrading bacteria. LDPE bags were present at varying depth of approximately 5-20 cm. About $1 \mathrm{~g}$ of soil was aseptically scratched from each buried LDPE bag and was transported to laboratory in sterile Ziploc plastic bag within $24 \mathrm{~h}$. At the time of sampling the soil temperature was $26-38^{\circ} \mathrm{C}$ and $\mathrm{pH}$ was $8 \pm 1$. Isolation of bacteria was done by serial dilution and spread plate technique using Tryptic Soy Agar (TSA). Each plate was incubated at $37^{\circ} \mathrm{C}$ until bacterial growth was appeared. All morphologically distinct colonies were sub-cultured to get pure isolates followed by preservation at $-80^{\circ} \mathrm{C}[5]$.

\subsection{Inoculum Preparation}

Bacterial isolates were initially cultured in sterile MSM (modified with $0.5 \%$ peptone) at $37^{\circ} \mathrm{C}$ for $24-48 \mathrm{~h}$ in order to make them adapt to this environment. After subsequent sub-culturing in the same medium, the mid log phase was analyzed by determining its growth curve. Each bacterial culture was harvested at mid log phase and cells were collected by centrifugation at 10,000 rpm for 3-5 min [8]. The bacterial cells were then washed with sterile MSM to remove any residual media that will serve as a source of carbon contamination. This procedure was repeated three times and the washed cells in the pellet were resuspended in sterile MSM.

\subsection{Screening and Preliminary Identification of Bacteria}

The cell suspension containing washed cells $(0.5 \mathrm{~mL})$ were homogenously spread on sterile MSM agar plates and sterile LDPE film was placed in the center. The uninoculated MSM plate containing only LDPE film was taken as sterile control. Inoculated MSM plate without LDPE film was used as control to check whether the isolates could grow on MSM alone [8]. Plates were incubated at $37^{\circ} \mathrm{C}$. Growth on LDPE films was preliminarily determined by observing the formation of a biofilm after 35-45 d. The growth of bacteria on the film showed its capability of degrading LDPE and was selected for further processing. The selected bacterial isolates were initially identified using Gram staining and then by Vitek 2 Identification System according to manufacturer's instructions (VITEK 2 Compact, Biomerieux, France).

\subsection{Molecular Identification of the Isolates}

The genomic DNA was extracted from fresh culture. The cells were lysed using conventional L6 lysis buffer (5.25 M GuSCN, $50 \mathrm{mM}$ Tris-HCl (pH 6.4), 20 mM EDTA, 1.3\% Triton X-100, distilled water). Amplification was performed using universal primers 27F 
(5'-AGAGTTTGATCMTGGCTCAG-3') and 1492R (5'-CGGTTACCT TGTTACGACTT-3'). A $50 \mu \mathrm{L}$ mixture was prepared for polymerase chain reaction (PCR) containing; $2 \mu \mathrm{L}$ of template DNA, $5 \mu \mathrm{L}$ of

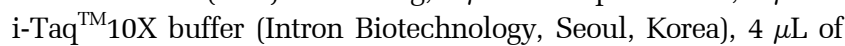
dNTP's, $2 \mu \mathrm{L}$ of each primer, $1 \mu \mathrm{L}(2 \mathrm{U})$ of TTaq $^{\mathrm{TM}}$ DNA polymerase and $34 \mu \mathrm{L}$ of nuclease free water. The PCR was conducted at following conditions: initial denaturation at $95^{\circ} \mathrm{C}$ for $5 \mathrm{~min}$, followed by 35 cycles of $94^{\circ} \mathrm{C}$ for $30 \mathrm{~s}, 55^{\circ} \mathrm{C}$ for $30 \mathrm{~s}, 72^{\circ} \mathrm{C}$ for $2 \mathrm{~min}$ and final extension at $72^{\circ} \mathrm{C}$ for $7 \mathrm{~min}$. The amplified product was analyzed and sequenced (Microgen Inc., Seoul, South Korea). The nucleotide sequences were analyzed and aligned using the CLUSTAL W program (BioEdit) and similarity search was conducted using BLAST of NCBI GenBank database. The phylogenetic tree was constructed using the Neighbor-joining method (MEGA version 7) after multiple sequence alignment with bootstrap value of 1000 replicates.

\subsection{Biodegradation Studies}

\subsubsection{Percent weight loss determination}

Sterile LDPE films $(2 \mathrm{~cm} \times 2 \mathrm{~cm})$ were pre-weighted and aseptically transferred to conical flask containing $100 \mathrm{~mL}$ MSM, as a sole carbon source. $5 \mathrm{~mL}$ of washed suspension (approximately $10^{8}$ cells per $\mathrm{mL}$ ) [8] were added to MSM containing LDPE film. Negative control was maintained having plastic film in medium without inoculation for further reference and to compare reduction in weight. The flasks were incubated at $37^{\circ} \mathrm{C}$ in shaking incubator for 90 d [2], at $100 \mathrm{rpm}$. For identifying any contamination in the medium, streak culture method was performed on TSA plates [21]. After incubation, the LDPE films were collected and washed thoroughly to remove cell debris with $2 \%$ Sodium Dodecyl Sulfate (SDS) solution for $4 \mathrm{~h}$ at $50^{\circ} \mathrm{C}$ followed by rinsing with sterile double deionized distilled water and $70 \%$ ethanol. All the films were dried overnight at $60^{\circ} \mathrm{C}$ before weighing and percent weight loss was calculated $[7,9]$.

\subsection{PCR Amplification of LDPE Degrading Gene(s)}

Total genomic DNA was extracted from bacterial isolates using Lysis buffer and the purified DNA was stored at $-20^{\circ} \mathrm{C}$ until used. DNA purity and concentration was determined using Nanodrop. Laccase and Alkane hydroxylase have been reported to be involved in enzymatic biodegradation of LDPE [14, 22, 26]. The genes for these enzymes were amplified using specific primers [29, 30], and conditions mentioned in Table S1 using the Program Temp Control system PC 707 (ASTEC, Fucota, Japan).

\subsection{Analytical Procedures}

\subsubsection{Field Emission Scanning Electron Microscopy (FE-SEM) analysis}

The LDPE films were analyzed to check for any changes in surface morphology (small holes, cracks and pits) after treating them with LDPE degrading bacteria. The air-dried samples were platinum coated (LICA EM ACE 600), and were then exposed to FE-SEM (SUPRA 55-VP, Carl Zeiss, Germany) [31].

2.8.2. Fourier Transform Infrared Spectroscopy (FTIR) analysis Changes in the structure of plastic films following UV irradiation and subsequent incubation with bacteria were analyzed using
FTIR spectrophotometer (Nicolet 6700, USA). Each sample was observed with a spectrum range from 4,000-650 $\mathrm{cm}^{-1}$. Carbonyl Index (CI) was calculated in order to measure the degree of biodegradation. The CI was calculated based on the relative intensities of the carbonyl group at $1,712 \mathrm{~cm}^{-1}$ and $\mathrm{CH}_{2}$ group at $1,462 \mathrm{~cm}^{-1}$ [32]. The equation (Eq. (1)) used to calculate CI is expressed as:

$$
\begin{gathered}
\text { Carbonyl Index (CI) }= \\
\text { Absorption at 1,712 } \mathrm{cm}^{-1} \text { (the maximum of carbonyl peak) } \\
\hline \text { Absorption at 1,462 } \mathrm{cm}^{-1} \text { (the maximum of carbonyl peak) }
\end{gathered}
$$

\subsubsection{X-Ray Diffraction (XRD) analysis}

The XRD pattern of the LDPE films was analyzed using X-ray diffractometer (Rigaku, SmartLab, Japan) after biodegradation. The scattered radiation was recorded with the range of 10-40 degrees two theta on the polymer films under constant operating conditions at room temperature [31]. Before processing our XRD data for the peak analysis to calculate the percent crystallinity, we did convolution and subtracted the background using Lab 6 software to minimize the error due to noise. Percent crystallinity for each sample was calculate separately, by processing the three peaks around 19, 21 and 23.7 at $2 \theta$ in the XRD data using originPro8.5 and the following equation (Eq. (2)).

Percent crystallinity $=(\mathrm{A} 2+\mathrm{A} 3) /(\mathrm{A} 1+\mathrm{A} 2+\mathrm{A} 3) * 100],(2)$

A1: Integrated area of the amorphous peak around $192 \theta$

A2 and A3: Integrated areas of the crystalline peaks.

\subsubsection{Total carbon analysis}

Total carbon was analyzed in LDPE film after incubation with the bacterial isolates. Uninoculated film was taken as control to compare percentage of total carbon reduced after biodegradation [33]. Approximately $10 \mathrm{mg}$ of LDPE film was cut into small pieces and analyzed using elemental analyzer (Flash EA1112, Thermo electron corporation, USA).

\section{Results and Discussion}

\subsection{Identification and Screening of Bacterial Isolates Capable of LDPE Biodegradation}

Many distinct colonies were observed on TSA plates after incubation at $37^{\circ} \mathrm{C}$ for 3-4 d. A total of thirty six morphologically distinct colonies were selected and sub-cultured for further screening. All bacterial isolates were screened for their degradation ability using MSM media and LDPE films. Clear growth was observed beneath the surface of LDPE films after $45 \mathrm{~d}$ of incubation at $37^{\circ} \mathrm{C}$ (Fig. 1). Out of total thirty six isolates, only six showed biofilm formation revealing their capacity to utilize LDPE as a carbon source and were further characterized. The biofilm formation on LDPE films determines its biodegradation potential because biofilm causes the bacteria to efficiently utilize the insoluble polymer substrate [34]. No bacterial growth was seen on either control i.e., MSM with a LDPE films but without inoculation and MSM without a LDPE film but with inoculation (Fig. 1 (g), (h)). 

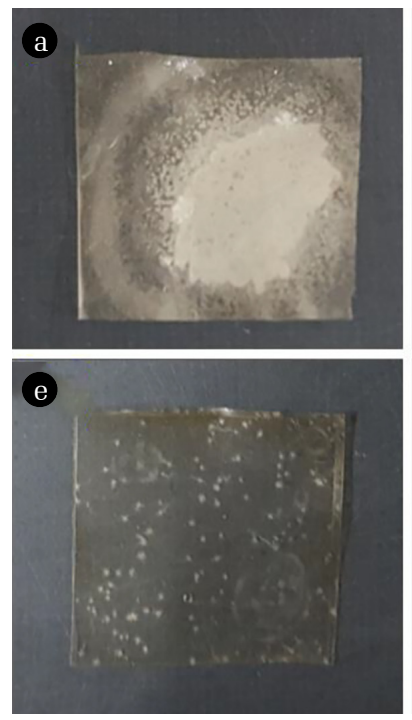
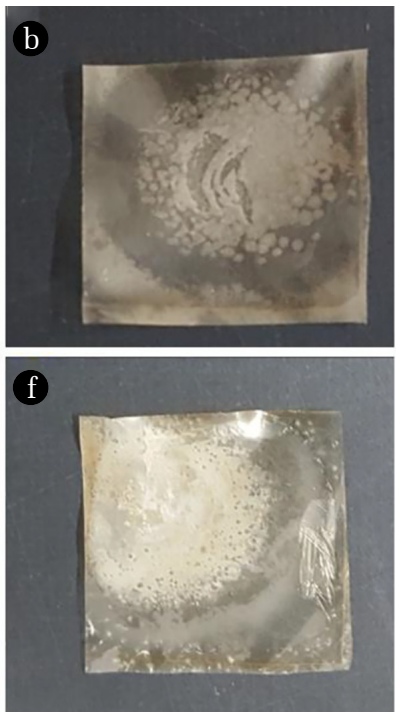
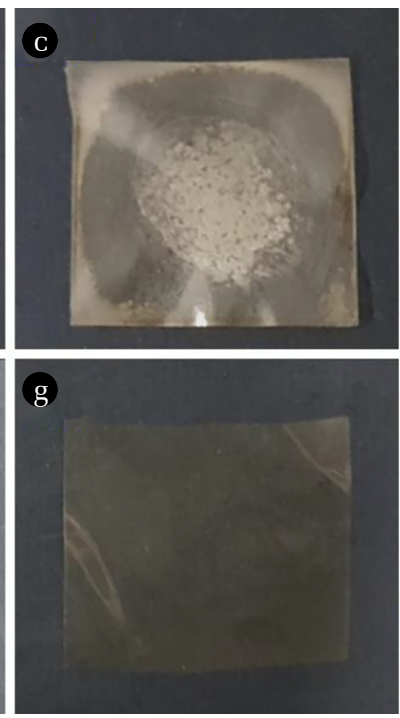
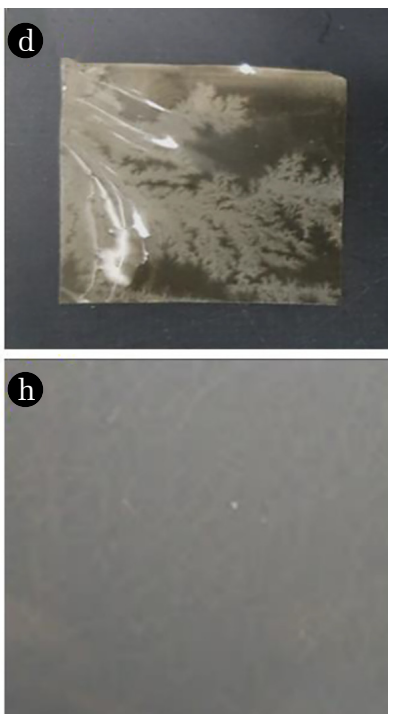

Fig. 1. Growth of bacterial biofilm on LDPE film's surface revealing their biodegradation ability. (a) B. wiedmannii, (b) B. cereus, (c) B. siamensis, (d) A. iwoffii, (e) P. aeruginosa, (f) B. subtilis, (g) Sterile Control, (h) MSM without LDPE film but with inoculation.

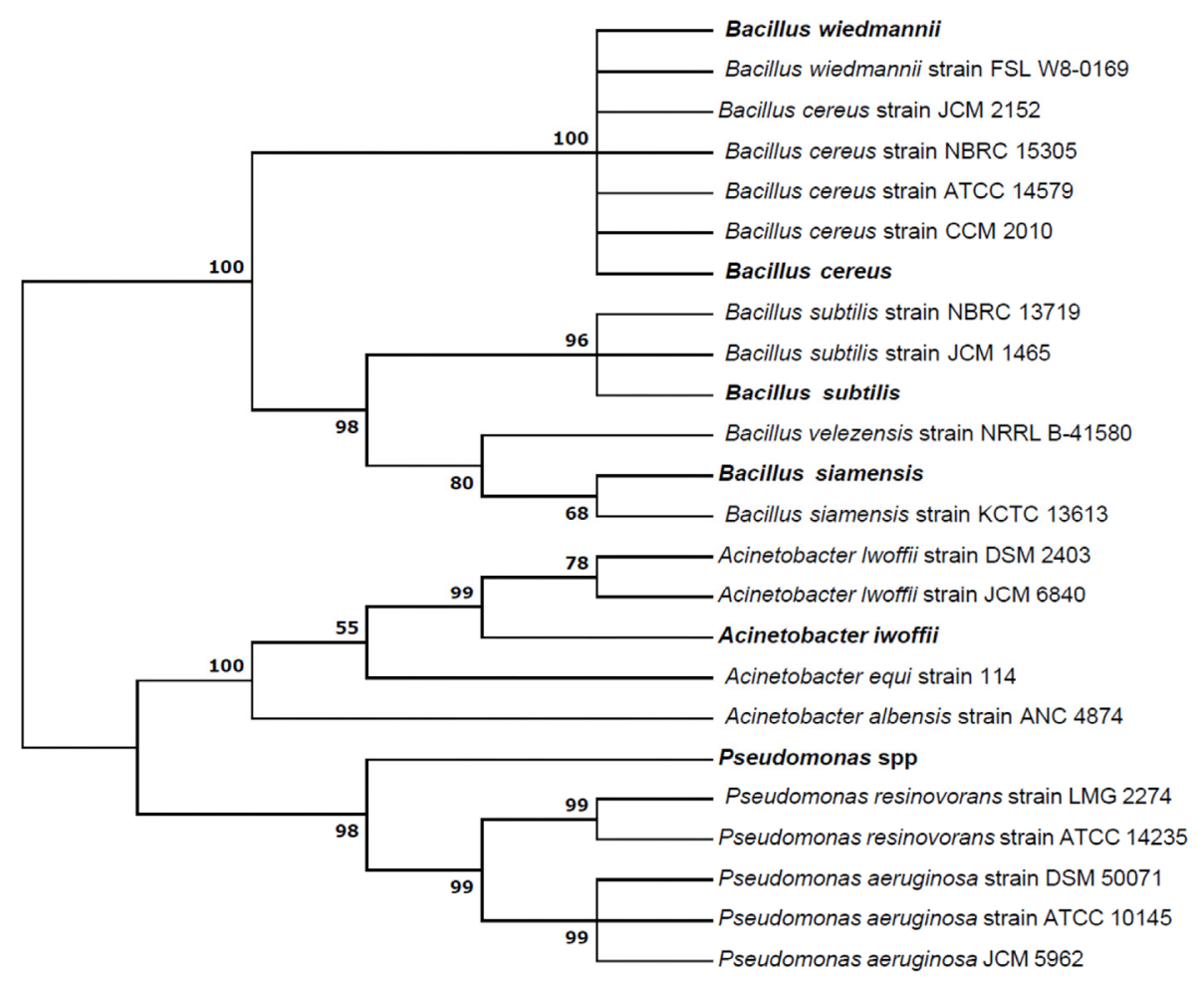

Fig. 2. Neighbor-joining phylogenetic tree of isolates based on 16SrDNA sequencing.

The bacteria isolated and identified in the current study were; Bacillus wiedmannii (NR152692.1, 100\%), Bacillus subtilis (CP020102.1, 100\%), Bacillus siamensis (KY643639.1, 99\%), Bacillus cereus (KY628813.1, 99\%), Acinetobacter iwoffii (NR113346.1, 99\%), Pseudomonas aeruginosa (CP012001.1, 97\%) and according to Vitek ${ }^{\mathrm{TM}}$ and $16 \mathrm{SrDNA}$ sequencing. The phylogenetic tree showing related species as per 16SrDNA sequencing is illustrated in Fig. 2.

\subsection{Investigation of LDPE Degradation}

The biodegradation of LDPE was monitored by weight loss estimation and was further confirmed by analytical procedures using FE-SEM, XRD, FTIR and total carbon analysis.

\subsubsection{Percent weight loss determination}

The identified bacterial isolates were tested for their degradation capacity that was measured in terms of percent weight loss (Table 1). 
Table 1. Percent LDPE Degradation of the Bacterial Isolates After 90 Days of Incubation

\begin{tabular}{lcccc}
\hline S. No & Sample & Initial weight (mg) & Final weight (mg) & Weight loss (\%) \\
\hline 1 & Bacillus siamensis & 100.0 & 91.54 & $8.46 \pm 0.3$ \\
2 & Bacillus cereus & 179.35 & 168.0 & $6.33 \pm 0.2$ \\
3 & Bacillus wiedmannii & 191.59 & 181.26 & $5.39 \pm 0.3$ \\
4 & Bacillus subtilis & 187.69 & 180.66 & $3.75 \pm 0.1$ \\
5 & Pseudomonas aeruginosa & 180.52 & 178.44 & $1.15 \pm 0.1$ \\
6 & Acinetobacter iwoffii & 185.92 & 184.5 & $0.76 \pm 0.1$ \\
7 & Negative Control & 159.24 & 159.0 & $0.15 \pm 0.1$ \\
\hline
\end{tabular}

The highest percent weight loss was presented by B. siamensis $(8.46 \pm 0.3 \%)$ followed by $B$. cereus $(6.33 \pm 0.2 \%)$, B. wiedmannii $(5.39 \pm 0.3 \%)$ and $B$. subtilis $(3.75 \pm 0.1 \%)$. Among bacterial isolates $P$. aeruginosa $(1.15 \pm 0.1 \%)$ and $A$. iwoffii $(0.76 \pm 0.1 \%)$ were not further investigated in this study as their percent weight reduction was negligible.

Bacillus species were more efficient in degrading LDPE films in this study as compared to other isolates. Several studies in literature also identified the potential of Bacillus spp for PE degradation via percent weight loss, such as Harshvardhan and Jha 2013, reported $1.75 \%$ in $30 \mathrm{~d}$ [7] and Yang et al. [8] observed $10.7 \pm$ $0.2 \%$ in $60 \mathrm{~d}$ of incubation. In the current study $B$. cereus showed $6.33 \%$ of weight loss of LDPE films (230micron), while previous study reported percent weight loss of $35.2 \%$ in 30 micron film after $120 \mathrm{~d}$ of incubation [35]. In present study, B. subtilis resulted in weight loss of $3.75 \pm 0.1 \%$, which is comparatively higher than $1.85 \%$ weight loss in $30 \mathrm{~d}$ of incubation [10] however another work reported $23.15 \%$ reduction in $60 \mathrm{~d}$ of treatment with $B$. subtilis [19]. The variation in percent weight loss in our study with comparison to literature might be attributed to the origin of bacterial isolates, film thickness and culture conditions such as incubation time. In this study, $B$. siamensis and $B$. wiedmannii resulted in the weight loss of $8.46 \pm 0.3 \%$ and $5.39 \pm 0.3 \%$, respectively. To the best of our knowledge, we are reporting $B$. siamensis and $B$. wiedmannii for the first time in LDPE degradation which exhibits the ability of utilizing LDPE as a sole carbon source.

As Laccase and Alkane hydroxylase have been known to be involved in enzymatic biodegradation of LDPE, their genes(s) were amplified in all the selected bacterial isolates. Amplified segments were subjected to agarose gel electrophoresis. Laccase (167 bp) was amplified and bands appeared in all isolates indicating their presence in them (Fig. 3 (a)) Moreover, two set of primers were used for Alkane hydroxylase amplification. B. subtilis and B. wiedmannii were positive for Alk 1 (330 bp), while $B$. cereus and $B$. siamensis showed the presence of Alk2 (185 bp) (Fig. 3 (b)). Production of extracellular enzymes plays an important role in biodegradation of PE through depolymerization [36] and are then enzymatically degraded into intermediate products that can be utilized as a carbon source [14]. Extracellular laccases and Alkane hydroxylase are among the enzymes implicated in LDPE biodegradation $[22,26]$. These enzymes have been reported in various bacteria, Brevibacillus borstelensis, Pseudomonas putida, Brevibacillus parabrevis and Bacillus cereus, for biodegradation of PE [14]. Alkane hydroxylase from Pseudomonas spp degraded $\mathrm{PE}$ by reducing its molecular weight indicating its capability in biodegradation [15, 26].

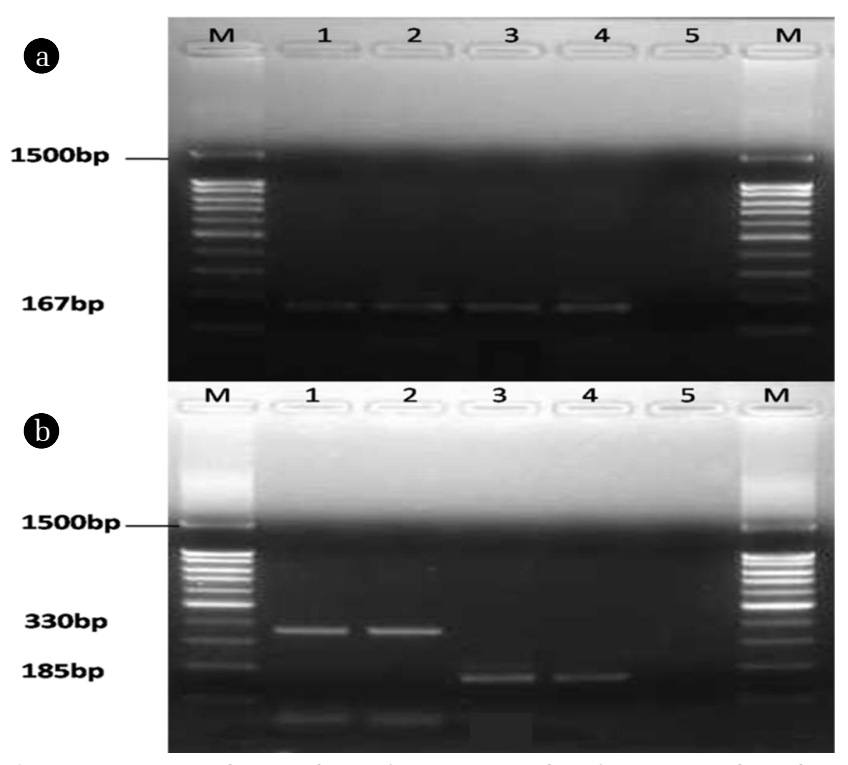

Fig. 3. (a) PCR product analysis of Laccase (167bp) from LDPE degrading bacteria, M: 100 bp Ladder; lane 1, B. subtilis; lane 2, B. wiedmannii; lane 3, B. subtilis; lane 4, B. siamensis; lane 5, Control and $M$, 100bp ladder. (b) PCR amplification of Alkane hydroxylase by Alk1 (330 bp) (lane 1-2) and Alk2 (185 bp) (lane 3-4); M, 100bp Ladder; lane 1, B. subtilis; lane2, B. wiedmannii; lane 3, B. cereus; lane 4, B. siamensis; lane 5, Control and M, 100 bp ladder.

\subsubsection{FE-SEM analysis}

Initial attack on LDPE films begins with surface colonization and penetration of bacterial isolates and these phenomena can be observed through FE-SEM. The treated LDPE films showed some physical changes (slight surface disruption) due to colonization of bacterial isolates, after $90 \mathrm{~d}$ of incubation. In contrast, the control retained a smooth surface under the same conditions (Fig. 4) These changes were not uniformly distributed on the entire surface as bacteria attached to only certain regions [37]. Similar observations have been reported in a previous study where formation of grooves were seen in the micrographs of LDPE films when treated with Pseudomonas sp AKS2 [38]. In one of the study Koutny et al. [39] reported that after $100 \mathrm{~d}$ of incubation with microorganisms, SEM analysis revealed no clear signs of bio-erosion on the surface of films. This study is quiet similar to our findings as our data suggest that bacterial action was only limited to the surface of LDPE film having slight surface disruption indicating biodegradation as a relatively slow and continuous process. 


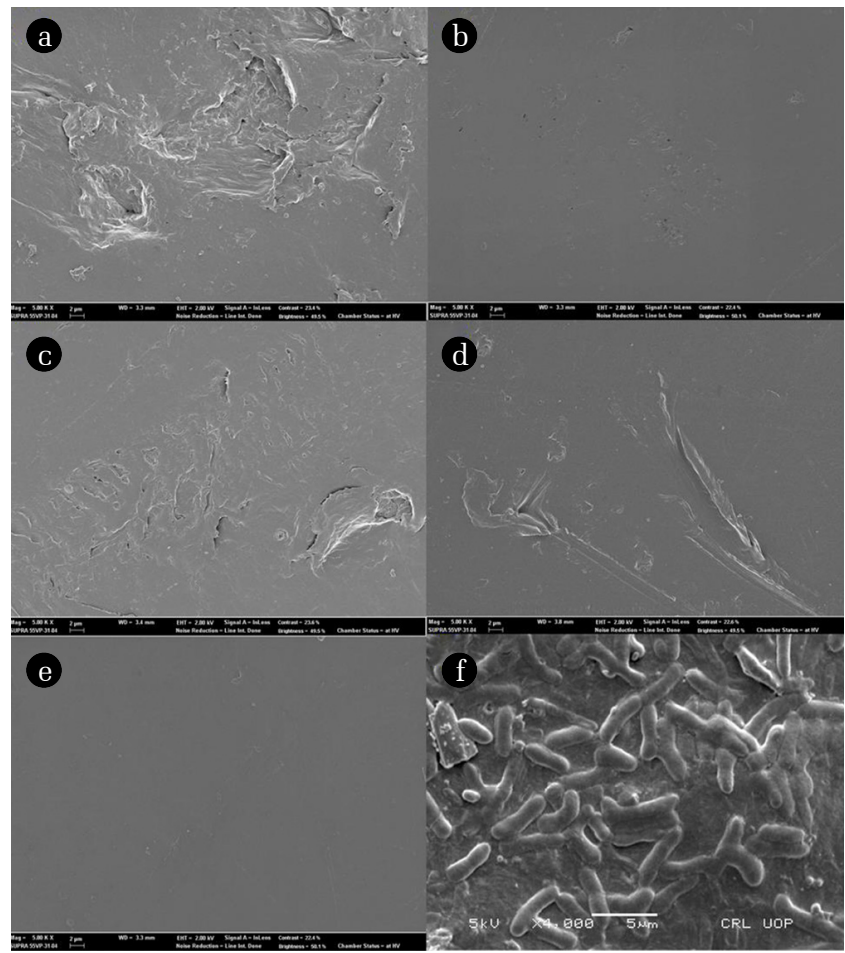

Fig. 4. FE-SEM micrograph of LDPE films after 90 days of incubation with bacteria showing slight surface disruption and small holes at $5.00 \mathrm{~K} \mathrm{X}$ magnification. (a) B. siamensis, (b) B. cereus, (c) B. wiedmannii, (d) B.subtilis, (e) Control, (f) Depiction of bacterial attachment to LDPE film at 4,000 K X magnification.

\subsubsection{FTIR analysis}

The exposure of LDPE films to UV radiations causes an increase in the carbonyl group and provides attachment sites for the bacteria [40]. The FTIR analysis of LDPE films were peformed to moniter the changes in carbonyl groups or double bonds which is essential to elucidate the biodegradation process. The FTIR spectra of LDPE films showed formation of typical carbonyl peak at $1,712 \mathrm{~cm}^{-1}$ (except untreated control), which was markedly reduced after 90 $\mathrm{d}$ of incubation with bacteria. This formation and disappearance of carbonyl peaks is essential to explicate the mechanism of plastic biodegradation [41] and the same phenomenon has been observed in our study where there is formation of carbonyl peak at 1,712 $\mathrm{cm}^{-1}$ which is reduced after treating with bacteria for $90 \mathrm{~d}$. The

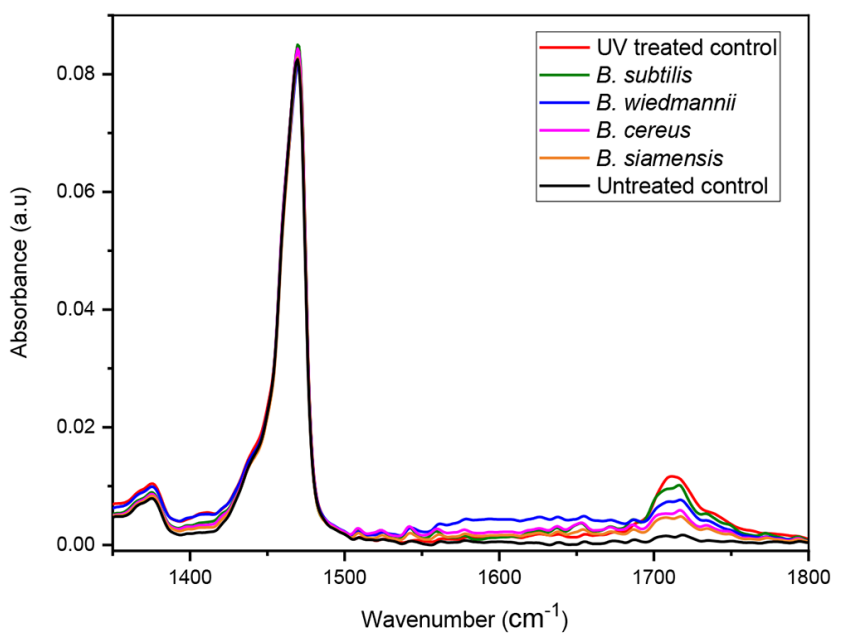

Fig. 5. FTIR spectra of LDPE films treated with bacteria; formation of carbonyl peak after pretreatment (UV treated control) and subsequent reduction in carbonyl peak with $B$. subtilis, B. wiedmannii, $B$. cereus and $B$. siamensis. No changes were observed in the untreated control.

same results have been reported by other researchers to monitor the formation or disappearance of functional groups to explain the mechanism of biodegradation process $[7,8]$, thereby supporting our results.

The formation and distinct reduction in the carbonyl residues (Fig. 5) was observed in all samples, suggesting microbial degradation. This reduction was also measured in terms of CI index as shown in Table 2. The maximum decrease in CI was observed for $B$. siamensis followed by B. cereus, B. wiedmannii and B. subtilis, showing $B$. siamensis has more potential for degradation. Several researchers also reported reduction in CI index values, suggesting microbial degradation, which may be due to the presence of oxidoreductases [21, 31].

\subsubsection{XRD analysis}

The percent crystallinity of LDPE films was increased after 90 $\mathrm{d}$ of incubation with selected bacterial isolates (Table 2 and Fig. S1). These results could explain the phenomenon that once polymer is exposed to microorganism it mainly attacks the amorphous regions (which is less resistant to microbial attack than crystalline regions), causing an increase in the overall crystallinity. Later with

Table 2. The Carbonyl Index, Percent Crystallinity and Total Carbon Percentages of LDPE Films Before and After Treatment with Bacteria for 90 Days

\begin{tabular}{lccc}
\hline Sample & $\begin{array}{c}\text { Carbonyl Index }(\mathbf{C I}) \\
\text { CI }=\mathbf{I 1} / \mathbf{I 2 a}\end{array}$ & $\begin{array}{c}\text { Crystallinity (\%) } \\
\text { [(A2 + A3)/(A1 + A2 + A3) * 100] }\end{array}$ & Carbon (\%) \\
\hline B. siamensis & 0.058489 & 35.35532592 & 85.5679 \\
B. cereus & 0.069845 & 31.46878474 & 85.6169 \\
B. weidmanni & 0.093827 & 31.15333231 & 85.4823 \\
B. subtilis & 0.119543 & 28.48387491 & 85.4114 \\
UV Treated control & 0.149755 & 27.92827197 & 85.3836 \\
Untreated control & 0.020487 & - & - \\
\hline
\end{tabular}

a : I1 = Intensity at $1,712 \mathrm{~cm}^{-1}$ and $\mathrm{I} 2=$ Intensity at $1,462 \mathrm{~cm}^{-1}$ 
the attack on smaller crystals located in the amorphous- crystalline phase or produced by initial consumption of amorphous phase, causes a decrease in crystallinity [42-44].

In a previous study an increase in the relative crystallinity of LDPE was observed in initial 3 months over treating with filamentous fungi [42]. Similarly Volke-Sepúlveda et al. [43] also reported an initial increase within 7-16 months of incubation by fungi followed by a decrease in crystallinity. In present study similar trend was observed by bacterial species in which the highest increase in percent cystallinity was shown by $B$. siamensis followed by $B$. cereus, B. wiedmannii and B. subtilis.

\subsubsection{Total carbon analysis}

In the current study there was no apparent change in total carbon (Table 2). This may be because of the short duration of incubation and thickness of the film as PE is hard to degrade and its degradation is a time dependent process. The negligible decrease in percent carbon content of 230 micron LDPE film was recorded, which is in contrast to a previously reported study in which author reported a decrease in carbon percentage from $93 \%$ to $91.7 \%$ and $91.6 \%$ to $90.1 \%$ for 20 and 40 micron PE film, respectively [33]. In another study different fungal strains resulted in significant decrease of total carbon of 15 micron thick PE sample [45]. The decrease in the carbon percentage may depend on the thickness of the film used.

\section{Conclusions}

In this study we isolated bacterial species from waste disposal sites of Peshawar, KP, Pakistan for LDPE degradation. We hereby conclude that the Bacillus species were capable of utilizing LDPE as a sole carbon source, as evidenced by various analytical tools; FE-SEM, FTIR, XRD and total carbon analysis. Among these species, $B$. siamensis and $B$. wiedmannii are reported for the first time that exhibit effective LDPE degradation, hence adding new information to the literature. Biodegradation was confirmed not only by the attachment of bacteria to the LDPE films and percent weight loss, but also by some physical and chemical changes in LDPE films like surface disruption, formation and reduction of carbonyl peaks, decrease in CI index and increase in percent crystallinity. There was negligible change in the total carbon content which attributes to the thickness of film used. The biodegradation by selected bacterial isolates was limited to surface of LDPE films and is relatively slow but continuous process. These isolates possesses LDPE degrading genes that encodes for enzymes Laccase and Alkane hydroxylase, which is the molecular explanation for the degradation of LDPE. In near future, different strategies are needed for optimum expression of these enzymes to increase and exploit their degradation potential.

\section{Acknowledgment}

This work was supported by Higher Education Commission (HEC) Pakistan, to be conducted in Lab of Infectious Diseases, Collage of Veterinary Medicine, Seoul National University. This study was partially supported by BK21 PLUS for Creative Veterinary Science Research and the Research Institute of Veterinary Science, Seoul National University, Republic of Korea. This article was presented at IWA $11^{\text {th }}$ Micropol \& Ecohazard Conference (2019) held on 20-24 October 2019 in Seoul, South Korea.

\section{Author Contributions}

L.M. (Ph.D. Student) conducted all the experiments. I.K. (Associate Professor, Ph.D) and B.A. (Professor) guided the author throughout the research. H.S.Y. (Professor) provided space and availability of the instruments in his laboratory with guidance throughout the research project. H.P (Ph.D. Student) and S.K. (Ph.D. Student) helped in the phylogenetic analysis of the isolates. S.A. (Assistant Professor) helped in conduct ing FTIR analysis through software.

\section{Nomenclature}

$\begin{array}{ll}\% & \text { Percentage } \\ { }^{\circ} \mathrm{C} & \text { Temperature (Degree centigrade) } \\ \mu & \text { Micro }(\mathrm{Mu}) \\ \Theta & \text { Theta } \\ { }^{1} & \text { Prime }\end{array}$

\section{References}

1. Sekhar VC, Nampoothiri KM, Mohan AJ, Nair NR, Bhaskar T, Pandey A. Microbial degradation of high impact polystyrene (HIPS), an e-plastic with decabromodiphenyl oxide and antimony trioxide. J. Hazard. Mater. 2016;318:347-354.

2. Kyaw BM, Champakalakshmi R, Sakharkar MK, Lim CS, Sakharkar KR. Biodegradation of low density polythene (LDPE) by Pseudomonas species. Indian .J. Microbiol. 2012;52:411-419.

3. Roy P, Titus S, Surekha P, Tulsi E, Deshmukh C, Rajagopal C. Degradation of abiotically aged LDPE films containing pro-oxidant by bacterial consortium. Polym. Degrad .Stab. 2008;93: 1917-1922.

4. Denuncio P, Bastida R, Dassis M, Giardino G, Gerpe M, Rodríguez D. Plastic ingestion in Franciscana dolphins, Pontoporia blainvillei (Gervais and d'Orbigny, 1844), from Argentina. Mar. Pollut. Bull. 2011;62:1836-1841.

5. Ojha N, Pradhan N, Singh S, et al. Evaluation of HDPE and LDPE degradation by fungus, implemented by statistical optimization. Sci. Rep. 2017;7:39515.

6. Albertsson A-C, Erlandsson B, Hakkarainen M, Karlsson S. Molecular weight changes and polymeric matrix changes correlated with the formation of degradation products in biodegraded polyethylene. J. Environ. Polym. Degrad. 1998;6:187-195.

7. Harshvardhan K, Jha B. Biodegradation of low-density polyethylene by marine bacteria from pelagic waters, Arabian Sea, India. Mar. Pollut. Bull. 2013;77:100-106.

8. Yang J, Yang Y, Wu W-M, Zhao J, Jiang L. Evidence of polyethylene biodegradation by bacterial strains from the guts of plastic-eating waxworms. Environ. Sci. Technol. 2014;48: 
13776-13784.

9. Das MP, Kumar S. An approach to low-density polyethylene biodegradation by Bacillus amyloliquefaciens. 3 Biotech. 2015;5:81-86.

10. Vimala P, Mathew L. Biodegradation of Polyethylene using Bacillus subtilis. Proc. Technol. 2016;24:232-239.

11. Abraham J, Ghosh E, Mukherjee P, Gajendiran A. Microbial degradation of low density polyethylene. Environ. Prog. Sustain. Energy. 2017;36:147-154.

12. Muthukumar T, Aravinthana A, Dineshram R, Venkatesan R, Doble M. Biodegradation of starch blended high density polyethylene using marine bacteria associated with biofilm formation and its isolation characterization. J. Microb. Biochem. Technol. 2014;6:116-122.

13. Skariyachan S, Patil AA, Shankar A, Manjunath M, Bachappanavar N, Kiran S. Enhanced polymer degradation of polyethylene and polypropylene by novel thermophilic consortia of Brevibacillus sps. and Aneurinibacillus sp. screened from waste management landfills and sewage treatment plants. Polym. Degrad. Stab. 2018;149:52-68.

14. Ndahebwa Muhonja C, Magoma G, Imbuga M, Makonde HM. Molecular Characterization of Low-Density Polyethene (LDPE) Degrading Bacteria and Fungi from Dandora Dumpsite, Nairobi, Kenya. Int. J. Microbiol. 2018;4167845.

15. Jeon HJ, Kim MN. Functional analysis of alkane hydroxylase system derived from Pseudomonas aeruginosa E7 for low molecular weight polyethylene biodegradation. Int. Biodeterior. Biodegrad. 2015;103:141-146.

16. Skariyachan S, Manjunatha V, Sultana S, Jois C, Bai V, Vasist KS. Novel bacterial consortia isolated from plastic garbage processing areas demonstrated enhanced degradation for low density polyethylene. Environ. Sci. Pollut. Res. 2016;23:18307-18319.

17. Nowak B, Pająk J, Drozd-Bratkowicz M, Rymarz G. Microorganisms participating in the biodegradation of modified polyethylene films in different soils under laboratory conditions. Int. Biodeterior. Biodegrad. 2011;65:757-767.

18. Skariyachan S, Setlur AS, Naik SY, Naik AA, Usharani M, Vasist KS. Enhanced biodegradation of low and high-density polyethylene by novel bacterial consortia formulated from plastic-contaminated cow dung under thermophilic conditions. Environ. Sci. Pollut.Res. 2017;24:8443-8457.

19. Ibiene A, Stanley H, Immanuel O. Biodegradation of polyethylene by Bacillus sp. indigenous to the Niger delta mangrove swamp. Niger. J. Biotechnol. 2013;26:68-78.

20. Suresh B, Maruthamuthu S, Palanisamy N, Ragunathan R, Pandiyaraj K, Muralidharan V. Investigation on biodegradability of polyethylene by Bacillus cereus strain Ma-Su isolated from compost soil. Int. Res. J. Microbiol. 2011;2:292-302.

21. Sudhakar M, Doble M, Murthy PS, Venkatesan R. Marine microbe-mediated biodegradation of low-and high-density polyethylenes. Int. Biodeterior. Biodegrad. 2008;61:203-213.

22. Santo M, Weitsman R, Sivan A. The role of the copper-binding enzyme-laccase-in the biodegradation of polyethylene by the actinomycete Rhodococcus ruber. Int. Biodeterior. Biodegrad. 2013;84:204-210.

23. Fujisawa M, Hirai H, Nishida T. Degradation of polyethylene and nylon-66 by the laccase-mediator system. J. Polym. Environ.
2001;9:103-108.

24. Sowmya H, Ramalingappa M, Thippeswamy B. Biodegradation of polyethylene by Bacillus cereus. Adv. Polym. Sci. Tech. 2014;4:28-32.

25. Rojo F. Handbook of Hydrocarbon and Lipid Microbiology. Springer, Berlin, Germany; 2010.

26. Yoon MG, Jeon HJ, Kim MN. Biodegradation of polyethylene by a soil bacterium and AlkB cloned recombinant cell. J. Bioremed. Biodegrad. 2012;3:1-8.

27. Gajendiran A, Krishnamoorthy S, Abraham J. Microbial degradation of low-density polyethylene (LDPE) by Aspergillus clavatus strain JASK1 isolated from landfill soil. 3 Biotech. 2016;6:52.

28. Lee B, Pometto AL, Fratzke A, Bailey TB. Biodegradation of degradable plastic polyethylene by Phanerochaete and Streptomyces species. Appl. Environ. Microbiol. 1991;57: 678-685.

29. Johnson SL, Daligault HE, Davenport KW, et al. Complete genome sequences for 35 biothreat assay-relevant Bacillus species. Genome Announc. 2015;3:e00151-00115.

30. Kohno T, Sugimoto Y, Sei K, Mori K. Design of PCR primers and gene probes for general detection of alkane-degrading bacteria. Microbes. Environ. 2002;17:114-121.

31. Esmaeili A, Pourbabaee AA, Alikhani HA, Shabani F, Esmaeili E. Biodegradation of low-density polyethylene (LDPE) by mixed culture of Lysinibacillus xylanilyticus and Aspergillus niger in soil. PLoS One. 2013;8:e71720.

32. Hadad D, Geresh S, Sivan A. Biodegradation of polyethylene by the thermophilic bacterium Brevibacillus borstelensis. J. Appl. Microbiol. 2005;98:1093-1100.

33. Ambika D, Lakshmi B, Hemalatha K. Degradation of low density polythene by Achromobacter denitrificans strain s1, a novel marine isolate. Int. J. Rec. Sci. Res. 2015;6:5454-5464.

34. Orr IG, Hadar Y, Sivan A. Colonization, biofilm formation and biodegradation of polyethylene by a strain of Rhodococcus ruber. Appl. Microbiol. Biot. 2004;65:97-104.

35. Muhonja CN, Makonde H, Magoma G, Imbuga $\mathrm{M}$. Biodegradability of polyethylene by bacteria and fungi from Dandora dumpsite Nairobi-Kenya. PLoS One. 2018;13.

36. Müller RJ. Biodegradability of polymers: regulations and methods for testing. Biopolymers Online. 2005;10.

37. Choi HS, Shin M-S, Kim J-H. Enhancement of Microbial Adhesion on the Chemically Modified Polyethylene Surface. Environ. Eng. Res. 1999;4:127-133.

38. Tribedi P, Sil AK. Low-density polyethylene degradation by Pseudomonas sp. AKS2 biofilm. Environ. Sci. Pollut. Res. 2013;20:4146-4153.

39. Koutny M, Sancelme M, Dabin C, Pichon N, Delort A-M, Lemaire J. Acquired biodegradability of polyethylenes containing pro-oxidant additives. Polym. Degrad. Stab. 2006;91:1495-1503.

40. Albertsson A-C, Karlsson S. The influence of biotic and abiotic environments on the degradation of polyethylene. Prog. Polym. Sci. 1990;15:177-192.

41. Selke S, Auras R, Nguyen TA, Castro Aguirre E, Cheruvathur R, Liu Y. Evaluation of biodegradation-promoting additives for plastics. Environ. Sci. Technol. 2015;49:3769-3777.

42. Manzur A, Limón-González M, Favela-Torres E. Biodegradation of physicochemically treated LDPE by a consortium of fila- 
mentous fungi. J. Appl. Polym. Sci. 2004;92:265-271.

43. Volke-Sepúlveda T, Saucedo-Castañeda G, Gutiérrez-Rojas M, Manzur A, Favela-Torres E. Thermally treated low density polyethylene biodegradation by Penicillium pinophilum and Aspergillus niger. J. Appl. Polym. Sci. 2002;83:305-314.
44. Weiland M, Daro A, David C. Biodegradation of thermally oxidized polyethylene. Polym. Degrad. Stab. 1995;48:275-289.

45. Zahra S, Abbas SS, Mahsa M-T, Mohsen N. Biodegradation of low-density polyethylene (LDPE) by isolated fungi in solid waste medium. Waste Manag. 2010;30:396-401. 